\title{
BIBLIOTECAS CONVENTUALES EN EL PERÚ. UN PATRIMONIO POCO EXPLORADO
}

Julián Heras, OFM

De todos es conocido el valor intrínseco de esta clase de bibliotecas, en cuyos anaqueles se conserva gran parte de la producción bibliográfica colonial. Sin embargo, estos fondos no siempre se hallan en las mejores condiciones ni se les estima como es debido, comenzando por los mismos interesados en su preservación. Claro está que lo que aquí diga sobre la revitalización de estas bibliotecas es a título personal y no represento a nadie; es de mi personal responsabilidad en mi condición de bibliotecario de convento y después de haber organizado varias bibliotecas conventuales, entre ellas la de Ocopa y la de los Descalzos de Lima.

Estas palabras mías tampoco quieren ser un tratado erudito sobre el origen, contenido y número de las bibliotecas conventuales del Perú. Sería materia de un libro y me faltarían datos para ello. Mi propósito es más concreto, constituyendo un llamado de urgencia a quienes son responsables de la conservación en las mejores condiciones de estas bibliotecas conventuales y eclesiásticas en general, que ya son patrimonio nacional.

No tenemos por qué insistir sobre su valor documental y bibliográfico, pues es bien sabido que fue en los conventos donde se formaron las mejores bibliotecas coloniales del Perú. Todas las órdenes religiosas compitieron en crear e incrementar las suyas, de suerte que se constituyeron en los mejores centros culturales del Perú pues muchas de ellas no solo sirvieron para el uso de sus propios religiosos, sino que estuvieron abiertas a los estudiosos. Estas bibliotecas conventuales se incrementaron tanto con fondos de tipo religioso o teológico, como de toda clase de obras filosóficas, científicas, literarias, históricas, etc., de manera que aun en temas no religiosos estaban al día.

He dicho que aquí no haré historia de las distintas bibliotecas conventuales, pero no podemos menos que dejar constancia de que fueron los jesuitas quienes poseyeron las mejores, como la célebre biblioteca del Colegio de San Pablo (15681767), antecedente de la Biblioteca Nacional de Lima', y que podría reclamar para sí uno de los primeros puestos en la vida académica del virreinato. Pero tampoco se quedaron a la zaga en este aspecto las demás órdenes religiosas establecidas en el Perú, como los dominicos, franciscanos, agustinos, mercedarios, carmelitas, de la Buena Muerte, etc. Ahí están todavía sus respectivas bibliotecas conservadas en Lima y en todos los conventos repartidos por el territorio peruano. Tal fue el interés que pusieron los religiosos en propagar el libro, que lo llevaron hasta los más apartados puestos misionales de la selva y no en pequeña cantidad. Aún se conservan listas de los libros trasladados a la selva, como el inventario hecho por los misioneros franciscanos de Ocopa conservado en la Biblioteca Nacional de Lima (C342), un tema que presento a los investigadores.

1 Luis Mantín. "La biblioteca del Colegio de San Pablo (1568-1767)". En fénix 25, Lima, 1971, pp. 25-36; Craciela Sánchez Cerro. "La fundación de la Biblioteca Nacional". En // Conercio, Lima 28 de julio de 1971, p. XXI. 
Mas estas bibliotecas conventuales sufrieron las mismas vicisitudes por las que han tenido que pasar los conventos del Perú a través del tiempo, desde la época colonial hasta nuestros días. Muchas han perdido, por diversas causas, sus mejores fondos bibliográficos, y otras han sucumbido.

"Las bibliotecas monásticas -ha escrito Guillermo Lohmann Villena- iban a ser, con el correr de los tiempos, las principales fuentes nutricias de las colecciones sobre las cuales basaron su caudal original las bibliotecas públicas de todos los países americanos durante el siglo pasado. Esta transferencia de los fondos no sólo se realizó en la capital, sino en muchos otros puestos del país"2.

Y las que se salvaron no siempre han merecido -salvo contadas excepciones- las atenciones necesarias para su incremento y buena conservación, cuando no han faltado ni faltan casos de un total abandono, constituyendo ello un atentado contra la cultura. $Y$ a remediar este estado de cosas poco edificante, que desdice de su brillante trayectoria y proponer remedios más urgentes, van dirigidas estas palabras. Decía en la Edad Media el célebre abad Tritemio:

"Fácilmente se echa de menos la disciplina de los monjes por sus bibliotecas... Tus códices te honran a ti cuanto tú les honras a ellos... En efecto: si tus volúmenes ruedan deshechos por las sillas, si están atestados de polvo, si involucrados de manchas por dentro y mal cuidados por fuera..., te llaman con voces desgarradoras iindocto, perezoso!..., aunque a ti mismo te llames doctor. El que trata negligentemente los libros divinos y humanos revela que en nada aprecia paciencia en ellos contenida" ${ }^{3}$.

Se podría multiplicar las citas y revisar la legislación de cada orden religiosa, en la cual con toda seguridad se disponía el buen mantenimiento e incremento de las bibliotecas conventuales en el pasado. Pero ello sería salirse del tema. Baste traer aquí unas palabras del padre franciscano Benjamín Gento al hablar sobre la importante biblioteca de San Francisco de Lima, hoy en proceso de catalogación a cargo del Instituto Nacional de Cultura:

"El cuidado de los libros o de las Librerías conventuales, como se llamaba a las bibliotecas, constituyó siempre, por lo menos entre los franciscanos, uno de los deberes principales de los Superiores. Lo mismo las diversas constituciones Generales de la Orden como las Ordenaciones Particulares de las Provincias y Estatutos de los Comisarios Generales del Perú y Patentes de los Provinciales, leemos con frecuencia normas, mandatos $y$ hasta excomuniones para custodiar los libros y las bibliotecas. Fuera cansado y monótono ir enumerando todas las disposiciones, mandatos, ordenaciones, etc., dados por los Superiores de la Orden para la buena conservación y continuo aumento de las bibliotecas conventuales, y entonces nos explicamos el por qué los Conventos poseen magnificas y excelentes Bibliotecas" 4 .

Algunas de las bibliotecas conventuales del Perú efectivamente han merecido el cuidado $y$ la atención de sus religiosos y se las ha conservado, ordenado e incrementado. En este sentido es ejemplar lo que se ha hecho con la del convento de Ocopa, una de las mejores bibliotecas conventuales y coloniales del Perú, pues además de haberse catalogado técnicamente está abierta al servicio de los estudiosos e investigadores ${ }^{5}$. Con la ventaja de su óptima conservación gracias al clima seco de la sierra. Pero las de Lima, con todo el polvo, humedad y polilla, ¿cómo se las conserva? No ignoramos los esfuerzos de religiosos que en cada convento se han preocupado por sus bibliotecas a través de su historia. Pero ello no es suficiente y se necesita la acción

2 Guillermo Lohmann Villena. "Libros, libreros y bibliotecas en la época virreinal". En Fénix 21, Lima, 1971, pp. 17-24.

3 Tritemio. De laude scriptorum manualium. Moguntiae, Opera, 1605, p.746.

4 Benjamín Gento. El Convento de San Francisco. Lima, 1945, p. 294.

5 Nora Córdova de Castillo. "La Biblioteca de Ocopa, su historia y organización". En Fénix 23, Lima, 1973, pp. 71-127. 
conjunta de los institutos religiosos para salvar estos tesoros invalorables para la cultura nacional. Porque la iglesia y las órdenes religiosas en el Perú nunca fueron ajenas a la cultura, sino todo lo contrario. En estas bibliotecas conventuales se formaron los religiosos que fueron luego eminentes catedráticos en las universidades antiguas del país. Debemos pensar, por tanto, que el acervo bibliográfico y documental que nos legaron nuestros antecesores es parte ya de nuestra cultura.

Es necesario, pues, que las órdenes religiosas sepan $y$ tomen conciencia del gran servicio que harían a la cultura si sus bibliotecas conventuales, convenientemente catalogadas e instaladas, estuvieran abiertas al público. A veces por ignorancia o intereses mal dirigidos se cometen verdaderos disparates con esta clase de bibliotecas. Se piensa que es dispendio de fuerzas $y$ dinero, cuando no evasión, dedicar parte del presupuesto a salvar obras del patrimonio eclesiástico o religioso $y$, con más razón, a promoverlo. Es no querer saber nada del pasado, como si el pasado les atara y no les dejara avanzar. Una biblioteca abierta en cada convento e iglesia sería la mejor prueba de democratización de la cultura. La promoción y puesta en servicio de estas bibliotecas sería lo ideal, y no desconocemos el interés de algún sector del clero por conservar este legado documental y bibliográfico.

Pero no basta con la tarea aislada de unos cuantos, es necesaria la acción conjunta de la Iglesia en general y de las órdenes religiosas en particular, que son las que mejores bibliotecas poseen aún. Sería conveniente que las mismas órdenes se organizaran para velar por la conservación de sus respectivas bibliotecas, y quién sabe si hasta se podría pensar en formar una gran biblioteca eclesiástica nacional, integrada por los mejores fondos bibliográficos coloniales. En ello no les faltaría a los religiosos, creo, ni el apoyo moral ni la técnica y ayuda económica necesarios.
Por ello creo necesario -como conclusión de este artículo- señalar los siguientes pasos tendientes a la mejor conservación de las bibliotecas conventuales:

- Concientización en el clero y especialmente entre los religiosos del valor de sus bibliotecas conventuales.

- Preparación de personal religioso en técnicas bibliotecarias y archivísticas.

- Inventario de todas las bibliotecas conventuales y de su estado actual.

- Catalogación de sus fondos y puesta en servicio de aquellas bibliotecas más importantes.

- Asesoramiento técnico y ayuda económica.

- Edición de catálogos especiales y publicaciones.

- Obtención, coordinación y canalización de información entre los responsables de estas bibliotecas.

- Tender a formar en Lima una Biblioteca Eclesiástica Nacional, preferentemente con fondos bibliográficos antiguos.

Una de las principales riquezas culturales del Perú -que envidian muchas naciones- es su patrimonio artístico, documental y bibliográfico, que en su mayor o buena parte es legado religioso transmitido por la Iglesia. Por ello la suplencia o ayuda del Estado y de las instituciones es de justicia. Baste con lo apuntado para despertar conciencias y promover acciones tendientes a proteger este patrimonio cultural encerrado en los conventos de incontrolados iconoclastas pasivos. Porque son iconoclastas no solo quienes destruyen el patrimonio documental, sino quienes debiendo tutelarlo no lo protegen. 